\title{
Experimenting with Contact Strategies in Business Surveys
}

\author{
Alfred D. Tuttle ${ }^{1}$, Jennifer L. Beck ${ }^{2}$, Diane K. Willimack ${ }^{1}$, Kevin P. Tolliver ${ }^{1}$, \\ Aryn Hernandez, and Cha-Chi Fan ${ }^{3}$
}

\begin{abstract}
The U.S. Census Bureau conducted a series of experiments to evaluate alternative contact strategies. We hoped to identify effective mail strategies that increase timeliness of response and reduce the number of cases receiving more-costly follow-ups. These experiments were incorporated into the collection of several annual business surveys and one quarterly survey. This article summarizes results from five experiments whose designs are based on business survey decision-making and response processes. We obtained clear, positive results from tests involving manipulation of mail sequences, but only modest results from tests in which we varied messages and envelope appearance, whose effects were seen only in specific industry subgroups.
\end{abstract}

Key words: Mail experiment; survey participation decision; reminder letters; mail sequence response enhancement.

\section{Introduction}

The U.S. Census Bureau decided to investigate alternative contact strategies to look for opportunities to improve the efficiency of its business survey collection operations. We hoped to identify effective mail strategies that increase timeliness of response and reduce the number of cases receiving more-costly follow-ups. After considering various possible strategies, we identified a few strategies to test in a round of experiments embedded in regular data collection operations. These strategies were selected based primarily on their feasibility in terms of integrating them into collection operations without major impacts to existing production schedules and resources. Additionally, some strategies were selected either because they showed promise based on prior research with household surveys, or because they were variations on strategies already used in production, but which had not been tested experimentally. Some of the research presented in this article has been reported previously (Langeland and Tuttle 2016; Hernandez et al. 2016).

The aim of these experiments is to test the effectiveness of select communication strategies to positively affect the decision to participate, namely by increasing the number

1 U.S. Census Bureau, 4600 Silver Hill Road, Washington, D.C. 20233, National Science Foundation, 4201 Wilson Blvd, Arlington, VA 22230, Federal Communications Commission, 445 12th Street SW, Washington, D.C. 20554, U.S.A. Emails: alfred.d.tuttle@census.gov, diane.k.willimack@census.gov, Kevin.P.Tolliver@census.gov, Aryn.Hernandez@census.gov, cha-chi.fan@fcc.gov

${ }^{2}$ National Science Foundation, 2415 Eisenhower Avenue, Alexandria, Virginia 22314. U.S.A. Email: jbeck@nsf.gov

${ }^{3}$ Federal Communications Commission, Washington, District of Columbia. U.S.A. Email: cha-chi.fan@fcc.gov Acknowledgments: Any views expressed are those of the authors and not necessarily those of the U.S. Census Bureau, the National Science Foundation, or the Federal Communications Commission. 
of responses and increasing the timeliness of response. We asked to what degree business survey respondents can be influenced 1) to respond (if they otherwise would not), and 2) to respond sooner? To begin to answer these questions, we must consider what is known about survey decision-making.

\section{Factors Affecting Business Survey Participation}

Groves and Couper (1998) and Dillman et al. (2009) describe respondent decision-making strategies based on rational choice models (cost-benefit analysis, leverage-salience, social exchange theory, etc.), according to which people decide whether to cooperate with a survey request based on systematic consideration of costs and benefits. That is, these models assert that respondents compare the cost of a survey request, such as their time and effort, perceived loss of privacy, and so on, with the potential benefits to themselves or to the larger society. Such models generally assume that respondents consider the information contained in survey invitations in making their decisions. We will briefly review research on business survey response and decision-making processes in order to understand what factors respondents may consider in deciding whether to cooperate with a survey request.

Willimack et al. (2002, see also Willimack and Snijkers 2013) conceptualize the decision whether to participate in a business survey as one based on an assessment of the burden of preparing the survey response in relation to the goals of the business. Businesses have two main goals - to provide goods and services, and to remain viable, that is, to produce goods and services at a cost below their sale value in order to make a profit. Respondents are typically information specialists whose primary responsibilities are to account for operational resources and expenditures, provide information to support management decision-making, and report externally to various regulatory or taxing authorities. Snijkers et al. (2007) state that, with regard to survey participation, what is central to businesses is reduction of costs associated with compliance; completing surveys is described by respondents as "very time-consuming and burdensome, and that they get nothing in return." Lorenc et al. (2012) tell us that respondents are usually not users of survey data - though such users may exist elsewhere in their organizations - so survey work is often perceived as having a direct cost without direct benefit. Informing respondents about the purpose or uses of a survey can reduce the perceived burden and suggests that increasing the perception of usefulness of business surveys might thus help achieve more accurate and timely reporting (Snijkers et al. 2007; Lorenc et al. 2012).

Let us examine the processes by which businesses respond to surveys to understand the costs of and the bases for decisions about survey participation. First, let us consider the actors involved. Bavdaž (2010) identified five roles in the business survey response process. It should be noted that individual actors may fill multiple roles depending on the business' size and organizational complexity, and the existence of survey response routines. The following is a description of Bavdaž's five roles and the parts they play in survey decision-making and response.

1. Gatekeepers are intermediaries between an organization and the external environment who screen requests and route them to appropriate decision-makers within the organization. Gatekeepers may include staff who process mail, personal or 
administrative assistants and receptionists who receive and filter mail and telephone contacts, and other personnel through whom survey requests are routed in the process of finding appropriate decision-makers. Gatekeepers may be formally or informally empowered to make decisions about survey requests on their own, and may autonomously disregard such requests. The process of finding the appropriate decision-makers to receive survey requests is not always straightforward, with the result that a survey can "float" around a business for some time, passing through many hands before reaching someone who will take responsibility for it (Willimack and Nichols 2010).

2. Authorities are company personnel (such as managers at various levels or authorized lower-level employees) who are entrusted by their organizations with the ability and responsibility to make decisions regarding appropriate uses of resources, including those needed for survey response. An authority may assign a survey request on the basis of likely respondents' knowledge of the survey topic, access to requested information, and availability with regard to the timing and estimated workload of the survey. An authority may decline survey participation, and formal policies may be in place to decline participation, for instance, in surveys that are not mandatory. In the case of larger businesses, survey requests may be routine, such that survey-related decision-making may rest formally or informally with lower-level personnel whose jobs involve some form of external reporting (Willimack and Nichols 2010).

3. Respondents are responsible for interacting with the survey instrument to understand the specifics of survey requests, obtain requested data, enter the data in the survey instrument, and ensure completion and submission of the survey. They may be assigned responsibility by an authority for completing a survey, or survey requests may come to them as a matter of routine.

4. Data providers are personnel with relevant knowledge and/or access to requested data not directly available to respondents, who support the process of completing a survey. They may be given a questionnaire or some portion of it (e.g., scanned or photocopied pages) or they may receive requirements for requested data as interpreted by respondents (e.g., in conversation, email, or ad hoc spreadsheets) to guide retrieval and facilitate return of the data (Willimack and Nichols 2010; Tuttle 2016).

5. Survey coordinators may be assigned to manage the process of completing and submitting a questionnaire, and obtain assistance from data providers. Often a respondent takes on this role to obtain data not available to them directly, but more complex surveys may be managed entirely by a coordinator with little or no involvement in interpreting requirements for requested data or retrieving the data. Keller et al. (2011) found that survey coordinators vary in terms of effort they put into ensuring the completeness and quality of data returned by data providers.

Tomaskovic-Devey et al. (1994) identified three dimensions that affect the ways these five types of actors carry out their tasks in business survey response processes: authority, capacity, and motivation (though it should be noted that the authors posit these dimensions as a way of explaining survey nonresponse). As indicated above, authority refers to the responsibility and power vested in a company representative to make decisions about whether to participate in a survey, and to delegate the response tasks to employees. 
Authority in this sense also includes the mandate that an employee has to carry out assigned survey work, which legitimizes requests to other survey actors for their assistance and compels their cooperation. In addition to assigning response tasks, a person in a position of authority may review responses for completeness, accuracy, and consistency with other externally-released information about the business, and order corrections prior to their release (Willimack and Nichols 2010).

Capacity describes the ability to complete a survey request. Capacity is dependent on several factors, such as the existence, composition and structure of records containing requested data; the respondent's knowledge of and proximity to such records; the knowledge of how the data contained in records relate to the organization's characteristics and behavior of interest to the survey; the ability to locate and obtain assistance from knowledgeable data providers elsewhere in the organization; and more. (Bavdaž 2010; Tuttle 2009). The burden associated with finding and coordinating support from multiple personnel is often described as a significant source of response burden (Tuttle 2009; Tuttle and Willimack 2012).

Various studies (Davis and Pihama 2009; HMRC 2010; McCarthy et al. 2006) have reported that businesses with a history of survey cooperation are more likely to participate in future requests. Such consistency of behavior over time is aided by the fact that, once the upfront investment is made in terms of comprehending the survey request, identifying data sources, and establishing retrieval procedures, response to similar requests in subsequent collection cycles is less burdensome (Willimack et al. 2002; Bavdaž 2010).

Tomaskovic-Devey et al.'s (1994) third dimension of business survey response is motivation. Motivation to respond to a survey can be affected by factors such as the perceived legitimacy of the survey sponsor, the perceived burden of the survey, norms of cooperation within an organization and in relation to its external environment, respondents' performance evaluation criteria, professional standards for data quality, and so on (Willimack et al. 2002). Torres Van Grinsven et al. (2012) distinguish intrinsic from extrinsic motivations with regard to business survey response. Extrinsic motivations are external to the respondent, for example, the fact that response to a survey is required by law, or has been assigned by a company authority. Intrinsic motivations arise within the individual respondent, and are affected by, among other things, a respondent's assessment of the requirements of the task relative to his or her ability to perform them. A respondent's sense of autonomy in completing work assignments, feeling of competence with regard to an assignment, and the degree to which she or he enjoys challenging tasks are examples of intrinsic motivation in relation to survey completion. Such motivations affect "not only the decision to participate in a business survey but also the [level of] commitment to the task, which affects the accuracy and timing of the response" (Torres Van Grinsven et al. 2012; see also Giesen 2012).

Government surveys often have an advantage with regard to motivating business survey participation, in that response may be required by law. For businesses, continued viability (one of their primary goals) requires some degree of sensitivity to legal requirements, and this is reflected in the relatively high response rates enjoyed by most mandatory government surveys (Haraldsen 2013). The benefit of clearly communicating a survey's mandatory status in terms of increasing response has been demonstrated in business surveys (Tulp et al. 1991; Snijkers et al. 2007) and in household surveys (Dillman et al. 
1996; Barth et al. 2016). The salience of obligatory government reporting is such that some business respondents operate under the assumption that all government surveys are mandatory (Torres Van Grinsven et al. 2012). Nevertheless, even mandatory government surveys do not have perfect response rates (Haraldsen 2013).

An important factor affecting the decision to participate in a survey and the capacity and motivation to complete it is the timing of a survey request. Willimack and Nichols (2010) note that surveys often arrive at busy times for respondents, when they are in the process of settling accounts and reporting to regulatory and taxing authorities. In addition to the large amount of work involved in closing annual, quarterly, and monthly accounting periods, publicly traded businesses in the United States, for example, will not complete statistical reports before they have completed mandatory reporting to the Securities and Exchange Commission. Respondents will also typically not release any information before accounts are closed and/or audited, since any figures obtained prior to these milestones may not be considered validated and final. As a result, survey response may be delayed, and eventually, survey requests may be overlooked and forgotten altogether.

It is clear from this brief review of the business survey literature that survey communications should aim to enhance the perceived benefit and reduce the perceived burden that respondents associate with a survey request (see also Snijkers and Jones 2013). However, respondents may make decisions based on other considerations aside from costversus-benefit, and they may not typically perform systematic and rational considerations of all factors related to survey requests. Groves and Couper (1998) acknowledge the use of heuristics, cognitive shortcuts used in place of systematic processing. Snijkers and Jones (2013) integrate findings from other disciplines about how people process information in making decisions: "When people are about to make a decision, they process just enough information (not more and not less), at a minimum level of effort, to ascertain what they need to know to make that decision."

Landreth (2003) noted that, when reading survey materials, recipients of household survey requests tend to look for "one or two highly salient, diagnostic pieces of information" to help them decide whether or not to participate. They often stop reading a cover letter, for example, and cease cognitively processing the request it contains when they feel they have gotten enough information upon which to base a decision. In an earlier report, Landreth (2002) identified several questions asked by household respondents that affected their decision whether or not to participate in a survey:

- Is this voluntary?

- How long will this take?

- What is this and what is it used for?

- Who is doing the survey?

- How will my information be handled?

- How was I chosen?

Business survey respondents also ask these questions and have other questions of their own, such as (Snijkers and Jones 2013):

- Is this a legal requirement? What will happen if I don't respond?

- What am I being asked to do, and when? 
- Will it be easy to complete the survey?

- Do I have the time to participate?

- Is the information being requested sensitive to my business?

- Will the survey organization keep my business' information secure?

- How does this relate to my business? Will this survey benefit my business?

- Will I hear anything about the results of this survey?

Providing satisfactory answers to these questions may encourage respondents to cooperate with a survey, while unsatisfactory answers can lead to quick decisions to refuse to participate.

Groves et al. (1992, based on Cialdini 1984; see also Snijkers and Jones 2013) discussed a specific type of heuristic based on principles of social influence and the role they may play in survey decision-making. Briefly, these principles are:

- Reciprocity - fulfilling a request with the expectation of a reward

- Commitment and consistency - complying with a request that is similar to past behaviors

- Liking - cooperating with a request because the requestor is perceived as likeable

- Authority - agreeing to a request because the requestor is perceived as legitimate or trustworthy, as well as able to compel cooperation, for example, through legal means

- Social proof - satisfying a request because of the perception that others in one's community or society have also done so

- Scarcity - consenting to a request because it is perceived as being a rare opportunity

These principles have been identified as factors affecting response decisions in various studies. For example, Snijkers et al. (2007) note the use of reciprocity in the form of providing prior results of a survey as having positive effect on response. Their analysis also finds that Statistics Netherlands telephone clerks' most effective strategies for getting respondents to cooperate are liking (speaking in friendly tones, listening to respondents' grievances, offering assistance), and authority (citing legal authority as a last resort). Groves et al. (1992) cite the authoritativeness of the survey organization as a key factor that mitigates the perceived burden associated with a survey request. Snijkers and Jones (2013) note that consistency may account for continued response over subsequent collection cycles.

The information-processing behaviors described above support the assertion that persuasive elements of communications should be more prominent than information that might have a negative effect on a decision to participate (Tuttle and Willimack 2005). However, any consideration of a survey request is dependent on respondents receiving, opening, and reading the invitation.

Two recent similar studies followed up with respondents and nonrespondents to investigate what they did (or did not do) upon receiving a household survey invitation, and found that significant proportions of nonrespondents reported receiving survey invitations but not opening them. In one study, the U.S. Census Bureau conducted a mail experiment to web-push strategies with the American Community Survey (ACS), a mandatory household survey, with a follow-up survey of ACS respondents and nonrespondents to better understand the effectiveness of the experimental treatments and reasons for 
response (mode choice) and nonresponse (Nichols 2012). In the other study (Lykes and Meyers 2017), an experiment embedded in a household customer satisfaction survey to test various types of envelopes was accompanied by a follow-up survey of respondents and nonrespondents.

Nichols (2012) found that of nonrespondents to the survey experiment, approximately $15-20 \%$ (across the four treatment groups of the experiment) remembered receiving the envelope but did not open it, and 54\% of nonrespondents in Lykes' and Meyers' (2017) study also did not open the invitation (a difference explainable by the fact that ACS is a mandatory survey, which is indicated on the envelope). Lykes and Meyers (2017) provided additional insights into the process of handling and reviewing the survey invitation and deciding whether to respond, which they refer to as an "open-rate funnel." Specifically, they found that:

- $54 \%$ remember receiving the envelope

- $45 \%$ said they opened it

- $36 \%$ said they read and understood it

- $10 \%$ said they started the survey

- $7 \%$ said they completed the survey

As the metaphor of the funnel suggests, this is a process in which sample units are lost at each step. From the original sample who were mailed the survey request, only $45 \%$ said they opened the envelope, nine percent opened the envelope but did not read the contents, and only seven percent ultimately completed the survey.

Lykes and Meyers report that in their study, of those who read the survey invitation, almost twice as many respondents as nonrespondents said they read the letter $(62 \%$ vs $33 \%$ ), while more nonrespondents said they "partially" read it (48\% vs 35\%). That is, nonresponders were more likely to skim the survey invitation and apply heuristics to make a decision. The authors note that, given some individuals' tendency to skim instead of reading thoroughly, as well as the attrition from step to step in the open-rate funnel, the contents of the survey materials "may not have a chance to 'hook' people." Lykes and Meyers also report that respondents were more likely to recognize the survey sponsor than nonrespondents, and this was a common reason cited for opening the envelope.

These studies found similar reasons for not opening the survey invitations, as summarized in Figure 1. Many of the reasons they cite point to factors described in the decision-making literature for both business and household surveys (and are related to the three Tomaskovic-Devey et al. 1994 dimensions):

- Time and effort are limited resources (capacity)

- Respondents anticipate burden (motivation)

- The identity of the survey sponsor is often not salient (authority)

- The survey request does not seem important (authority)

In business surveys, these factors may apply to all five types of actors in the response process as described above.

A third study examined reasons for nonresponse to an establishment survey (Erikson and Hartwig 2012). Statistics Sweden conducted an experiment to test an improved survey invitation letter. The new invitation letter was designed to be aesthetically pleasing and 


\begin{tabular}{|c|c|c|c|}
\hline \multicolumn{2}{|l|}{ Nichols 2012} & \multicolumn{2}{|l|}{ Lykes and Meyers 2017} \\
\hline \multicolumn{4}{|c|}{ Remembered receiving invitation but did not open: } \\
\hline \multicolumn{2}{|l|}{$\begin{array}{l}14.8-20.6 \% \text { across four treatment } \\
\text { groups } 1\end{array}$} & \multicolumn{2}{|l|}{$54 \%^{2}$} \\
\hline \multicolumn{4}{|c|}{ Did not open invitation because: } \\
\hline $\begin{array}{l}\text { Too busy } \\
\text { Haven't gotten to it } \\
\text { Forgot about it/lost it/threw it } \\
\text { out } \\
\text { The mailing looked like junk } \\
\text { mail } \\
\text { Not familiar with the Census } \\
\text { Bureau }\end{array}$ & $\begin{array}{l}\sim 40 \%^{3} \\
\sim 10 \%^{3} \\
\leq 6 \%{ }^{3} \\
\leq 6 \%{ }^{3} \\
\leq 6 \%{ }^{3}\end{array}$ & $\begin{array}{l}\text { Too busy/no time } \\
\text { Recognized it as a survey and } \\
\text { didn't want to do it } \\
\text { Looked like junk mail/solicitation } \\
\text { Not important/worthwhile } \\
\text { Didn't know what it was }\end{array}$ & $\begin{array}{l}32 \% \\
19 \% \\
14 \% \\
9 \% \\
7 \% \\
\end{array}$ \\
\hline \multicolumn{2}{|c|}{$\begin{array}{l}\text { Read invitation but did not respond } \\
\text { because: }\end{array}$} & & \\
\hline $\begin{array}{l}\text { Thought the survey might } \\
\text { have been a scam } \\
\text { The survey was too long, } \\
\text { looked too big or looked like } \\
\text { too much work } \\
\text { They were confused }\end{array}$ & $\begin{array}{l}\leq 5 \%{ }^{3} \\
\leq 5 \% \%^{3} \\
\leq 5 \% \%^{3}\end{array}$ & & \\
\hline $\begin{array}{l}{ }^{1} \text { Denominators are the sample } \mathrm{f} \\
{ }^{2} \text { Denominator is sample for the } \\
{ }^{3} \text { Denominator contains all nonr }\end{array}$ & $\begin{array}{l}\text { r each ex } \\
\text { urvey reg } \\
\text { spondent }\end{array}$ & $\begin{array}{l}\text { gerimental treatment. } \\
\text { ardless of experimental treatment. } \\
\text { regardless of experimental treatme }\end{array}$ & \\
\hline
\end{tabular}

Fig. 1. Stated reasons for nonresponse from two studies.

contained a message stating that the actual burden of the survey would be much lower than the bulky questionnaire would suggest. The new letter did not obtain significantly better response than the original letter. In debriefings with respondents and nonrespondents, they found that many did not open the letters. The main reasons the authors cited are that respondents thought it was a waste of time; they do not respond to surveys as a matter of policy; and they thought it was "commercial stuff (junk mail)." The findings from this study of an establishment survey are consistent with those of the household studies and with the broader theoretical basis for survey decision-making. Together, these studies suggest widespread use of heuristics rather than systematic processing, resulting in quick decisions not only to decline survey requests, but also to avoid even considering the request.

\section{Operationalizing Contact Strategies}

\subsection{Awareness Model}

We conceive of the survey decision-making process as a series of steps leading from receipt of the request to execution of actions to respond, with each step dependent on 
successful completion of the preceding step. Our model of survey communication and action is thus (note the similarity of our model to those developed by early marketing pioneers, as described in Barry 1987):

Awareness of request $\rightarrow$ Consideration of request $\rightarrow$ Prioritization of request $\rightarrow$ Action

Every step of our model presents opportunities for intervention intended to increase chances for successful response. Each step is applicable to one or more of the five types of actors in the process. The communication strategies in our experiments are designed to influence these steps and obtain the following outcomes:

- Ensure awareness of the request

- Promote prompt consideration of messages

- Make the survey a higher priority

- Effect commitment to timely response

Let us elaborate on our model in the context of business survey roles and decisionmaking processes.

As noted above, a mailed survey request is subject to typical mail handling procedures within a given business entity. The number of steps and personnel involved in routing survey requests to a decision-maker depends on the size and complexity of a particular business and whether responding to surveys is a routine activity or a rare event. Our ability to affect awareness of survey requests is mitigated by these processes, which can vary greatly from business to business, and may be rife with potential breakdown points.

The envelope may provide enough information to route the envelope to a group responsible for handling government communications and/or external reporting. Information typically found on envelopes includes:

- Return address information and other text indicating official government mail from the Census Bureau;

- The addressee is a named business unit, which can be the enterprise as a whole or a specific sub-unit;

- Text indicating a due date and (if applicable) that response is legally required.

The envelope may contain sufficient information such that the request may be forwarded directly to a decision-maker. However, if the envelope does not provide enough information to facilitate finding a likely recipient, a gatekeeper may open it and look for additional clues. In this case, a gatekeeper can learn that the request is a survey, the topic of the survey, whether response is mandatory, and a web address and a telephone number to find more information on the nature of the request and the intended recipient. The due date and, if applicable, mandatory response requirement are prominent features of Census Bureau survey letters, and may provide sufficient motivation to find the intended recipient.

In larger businesses, there may be multiple gatekeepers involved in the process of getting the request to an appropriate decision-maker, and it is possible that any gatekeeper along the way may discard or lose a survey request. Another significant challenge to the process of a request reaching a decision-maker is the frequent turnover of company 
personnel, as employees leave or change jobs within a business (Willimack et al. 2002). This is especially a problem for recurring surveys addressed to previous respondents.

In the course of exploratory research conducted by the U.S. Census Bureau (Tuttle 2011), we learned from respondents that survey requests often reach them late, even after the due date, or that their first awareness of a survey request is through a reminder mailing or a telephone call from a survey analyst because a request never reached them. Some received only the critical document - that is, the request letter or questionnaire - as the envelope and enclosures such as pamphlets were discarded by gatekeepers along the way. In some cases, unfulfilled survey requests have been found among the documents left by a departing employee, and in one case, a request was found to have slipped behind the former employee's desk. Congruent with findings from Erikson and Hartwig (2012), in smaller businesses and others in which requests from the government are not expected, the official nature of such requests may not be recognized or may be suspected to be junk mail, and discarded without consideration. Upon reaching a decision-maker, a survey request letter may end up in a crowded inbox and compete for attention with other, more urgent documents, with the result that consideration is delayed until the period of heightened workload has ended.

As we discussed above, business survey decision-makers are primarily concerned with allocating resources to meet the needs of their organizations. As survey requests incur costs without direct benefits to a business, they are thus of a much lower priority than those related to formal duties. Depending on the nature of the survey request, namely the timing of receipt and due date relative to their concurrent workload, decision-makers may be unlikely to initiate survey response preparation until their work slows down. Unfortunately, statistical publication deadlines and other logistical considerations may preclude a survey agency from delaying the start of collection until after businesses' peak workload subsides.

As noted earlier, it may be possible for surveyors to affect the calculus of survey participation decisions by providing information that increases the perceived benefit of the survey and reduces the perceived burden. In addition, mail materials and strategies may be designed in such a way as to attract attention and increase their perceived legitimacy and importance. Taking all considerations as discussed above into account, as well as the Census Bureau's current suite of mail contact strategies, we identified opportunities to test the following strategies experimentally, namely:

- Appearance of the envelope

- Sequence of contacts

- Messages

Each of these strategies is discussed in detail in the following sections.

\subsection{Experimental Designs}

\subsubsection{Contact Strategy \#1: Appearance of Envelope}

The envelope conveys the initial impression of a survey request and thus represents the first opportunity to affect the decision-making process. The envelope should provide 
information that demonstrates the legitimacy of the survey organization, helps distinguish it from junk mail, and enables gatekeepers to forward it to an appropriate respondent or other decision-maker (Snijkers and Jones 2013; Dillman et al. 2009). The Census Bureau's business survey mailing envelopes typically contain the return address indicating that they come from a government agency. Other messages are often printed on envelopes, especially an indication that response is required by law, and sometimes the due date, depending on the decisions made by individual programs.

Survey response is significantly improved simply by printing a statement that response is required by law on the envelope, both for household surveys (Leslie et al. 2004; Barth et al. 2016) and business surveys (Tulp et al. 1991). Other studies have also shown the effectiveness of changing the appearance of envelopes in other ways. In an experiment with the Census Bureau's Economic Census of businesses, Marquette et al. (2015) demonstrated that sending reminder letters via U.S. Post Office certified mail, for which the envelopes had a prominent green sticker indicating that the reminder was different from the previous letters, was effective in increasing response among late responders. Lykes and Meyers' (2017) market research survey experiment tested various types of envelopes, and found that unusual envelopes - a larger bubble wrap envelope, and an envelope that mimicked the appearance of U.S. Post Office "priority mail" - resulted in higher response than plain white and colored standard size envelopes.

We decided to test two variations of our mail envelopes. In the first of these experiments, we created a treatment in which the due date, appearing below text indicating that response is required by law, was printed in red ink, to compare its effectiveness against the typical black ink (see Figure 2).

We based the second experiment on findings from focus groups with Economic Census respondents, who suggested that a larger envelope might increase the perceived importance of the mailing (Keller 2015). For this experiment, we compared the effectiveness of half-page-sized envelopes (9.5"x6") against the standard letter-sized envelopes (9.5"x4").

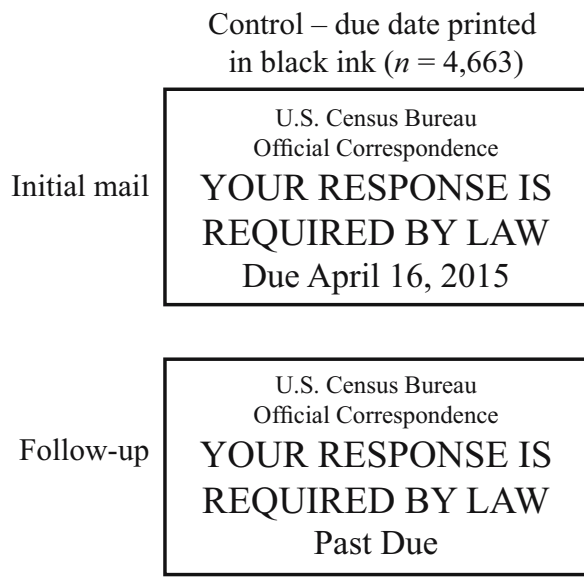

Treatment - due date printed in red ink $(n=4,661)$

\begin{tabular}{c}
\hline U.S. Census Bureau \\
Official Correspondence \\
YOUR RESPONSE IS \\
REQUIRED BY LAW \\
Due April 16, 2015 \\
\hline
\end{tabular}

\begin{tabular}{c} 
U.S. Census Bureau \\
Official Correspondence \\
YOUR RESPONSE IS \\
REQUIRED BY LAW \\
Past Due \\
\hline
\end{tabular}

Fig. 2. Imprinted due date/past due messages on 2014 AWTS envelopes. 


\subsubsection{Contact Strategy \#2: Sequence of Contacts}

Dillman et al. (2009) advise that the strategy for designing a sequence of survey contacts should attempt to realize an "additive effect" through their cumulative impact. That is, nonrespondents should receive reminders before the previous contact is forgotten. The literature provides many examples of the effectiveness of increasing the number and frequency of contacts both for household surveys (Barron et al. 2012; Chun and Robertson 1995; Crawford et al. 2001; Franklin et al. 2007; Hughes and Tancreto 2015, Kaplowitz et al. 2004; Matthews 2012; Reiser 2013; Shih and Fan 2008; Tancreto 2012; Zotti et al. 2016) and business surveys (Britt and Featherston 2007; Claveau and Turmelle 2012; Groves et al. 1997; Tuttle et al. 2010). These studies generally indicate that increasing the number and frequency of contacts has a positive effect on response, though results vary with regard to which types and combinations of contacts were found to be effective.

The sequence of contacts is of special concern for business surveys, which are often mailed during periods of heightened workload for respondents (Willimack et al. 2002). Ideally, the timing of reminders for business surveys should be tailored based on individual businesses' characteristics and response history, to estimate the best time to send mailings and reduce the number of follow-ups needed (Snijkers and Jones 2013). However, a tailoring strategy was not feasible for these experiments in light of the additional resources that would be required.

We conducted two experiments to test the effectiveness of enhanced contact sequences. On reviewing our current survey contact schedules, we considered whether our mailings were too far apart to achieve an additive effect. A typical mail schedule has an initial mail letter sent six to eight weeks before the survey due date, a first reminder letter four weeks or so after the due date, and one or more subsequent reminder letters mailed at intervals of four or so weeks thereafter, followed by telephone reminders to select companies based on importance for published estimates. This seemed to be a long time between contacts. Thus, one experiment added a pre-due-date reminder letter after the initial letter and about two weeks before the due date. The second experiment included a similar pre-due-date reminder as well as post-due-date reminders on accelerated schedules, moving them up by about two weeks.

\subsubsection{Contact Strategy \#3: Messages}

Snijkers and Jones (2013) state that the purposes of survey communication are to effect commitment to responding and provide information about measures intended to facilitate response; these purposes form the basis of messages used in our experiment. As noted earlier, the commitment to respond to a survey can be affected by the perceived burden, and that perceived burden can be reduced by enhancing the perceived value of the survey (Willimack et al. 2002; Snijkers et al. 2007; Lorenc et al. 2012).

A small body of research has shown that messages contained in mail contacts may positively affect survey participation, though results from various studies have been mixed. As noted above, one of the types of information that household survey respondents seek in survey requests addresses the purpose of the survey. More recent research with household respondents corroborates this finding (Eggleston et al. 2016; Fulton et al. 2016; Lor et al. 2017). In research with a business labor survey, Groves et al. (1997) found some 
indication that the communications containing the greatest amount of information about the survey and the surveying agency achieved higher cooperation as firm size increased. More recent research with a business labor survey found that alternative experimental treatments involving an enhanced letter and an enhanced letter in combination with an informational flyer increased response especially among smaller businesses, businesses in smaller cities and rural areas, and among certain industries (Perrins et al. 2009; Phipps et al. 2008).

Hedlin et al. (2008) conducted a study on an establishment survey in which messages explaining the purpose of the survey were sent to respondents. Although there was no demonstrable effect on response rates of such messages, they found in a post-survey follow-up that respondents who received results from past surveys were more likely to find the survey useful. These examples support assertions by Groves and Couper (1998) and Dillman et al. (2009) that survey participation can be enhanced by raising the perceived benefit of the survey and the uses to which results are applied. However, other research at the Census Bureau (Dillman et al. 1996) found that more detailed messages about the benefits of survey participation did not significantly improve response.

Snijkers and Jones (2013) observe that evidence on the effectiveness of mail enclosures included in business survey requests is limited and are skeptical about their utility, citing their own experience that such materials are often ignored, discarded, or lost as a survey request changes hands in a company.

We decided to test messages in flyers included with survey letters intended to promote the value of the survey and of the Census Bureau's mission, to offset the perceived burden of cooperating with the survey. One such flyer describes the uses of the survey and presents some survey results, including a graph showing the changing economic activity for selected industries over a period of several years. The second flyer is not surveyspecific, but describes an online tool developed by the Census Bureau intended to provide information for entrepreneurs looking to open or expand their businesses, as an example of the value of Census Bureau data products more generally. A third flyer attempts to reduce perceived burden by illustrating the steps of accessing the online reporting system and listing the advantageous features of the electronic reporting system. Census Bureau business surveys have long included flyers of the latter type as we have attempted to increase usage of our electronic reporting options over the years, though they have generally been rather plain. The design of these new flyers is consistent with Snijkers and Jones (2013)'s recommendations for presenting persuasive information, and use colorful graphics intended to be eye-catching and aesthetically pleasing.

We incorporated experiments to test these strategies into several annual surveys and one quarterly survey. The next sections provide an overview of the experimental methods and summarize the results from the individual experiments.

\section{Methodology}

The experiments presented in this article explored changes to the typical contact strategies for each survey program. These contacts include mail as the primary contact mode and telephone reminders for priority cases. Companies are initially mailed a survey invitation, and nonrespondents are mailed one or more post-due-date follow-up reminders. The initial 
mail contact is a letter notifying the respondent that they have been selected to respond. This letter also contains information about the survey (including legal authority and reporting requirements), the due date, and information for accessing an electronic reporting instrument. Subsequent letters inform the business of the delinquent response and encourage response. Telephone nonresponse follow-up (TFU) usually occurs after the final mailed follow-up reminder. TFU cases are prioritized on the basis of their impact on estimates.

With one exception (described later), all of the surveys in these experiments have multiyear samples. Thus, for the most part, the businesses in these experiments have received survey requests before or responded in prior years. Also, as noted above, staffing changes often result in different respondents or contact persons receiving and responding to survey requests. It was within this basic contact strategy framework that we conducted the five experiments.

In each experiment, cases were randomly assigned to treatment and control groups. This was accomplished by randomly sorting each sample by Employer Identification Number (EIN) or a survey control number, which are unique identifiers for each sample unit, and systematically assigning them to the groups in each experiment. The resulting samples were tested to ensure balance with regard to certain factors to control for differences that may bias the results of the experiments (where applicable):

- Survey units sampled with certainty vs. non-certainty, which is based on each unit's impact on survey estimates

- Prior year response status (response vs. nonresponse)

- Industry subgroups with variations in types of data collected

In most experiments, small numbers of special cases were excluded from assignment to the experiment groups because of special efforts to facilitate their response on the part of the survey programs. These include:

- Businesses with special mailing arrangements for multiple reporting units

- Cases assigned to staff who provide personal assistance for companies with the greatest impact on estimates

- Business locations with new or reactivated EINs

Cases of these types were excluded in order to avoid any confounding effects of special communication strategies and to minimize impacts on data collection operations. We acknowledge the potential bias of excluding these types of cases, especially larger businesses and those having a greater impact on published estimates, but assert that our experiments maintain internal validity because of their randomized design.

Because we were interested in how the treatments would affect response, in all five experiments we evaluated return rates, which represent the percentage of mailed cases that provided a response (as defined by Snijkers and Haraldsen 2013). In this article, we do not report results based on whether responses were considered complete (i.e., containing minimal required data) or weighted responses indicative of a unit's impact on published estimates. For some experiments, we also examined response latency. The use of different analytical methods, which included logistic regression and analysis of variance (ANOVA) reflect the different priorities of the survey programs for decision-making. 


\section{Results}

\subsection{Contact Strategy \#1: Appearance of the Envelope}

We conducted two experiments to evaluate differences in the appearance of the envelope.

\subsubsection{Envelope Experiment \#1: 2014 Annual Wholesale Trade Survey}

The Annual Wholesale Trade Survey (AWTS) is an annual survey of businesses in the wholesale trade sector collecting sales, purchases, inventories, and expenses. In the 2014 AWTS experiment, we compared the use of red ink to the standard black ink in an imprinted due date/past due notice on the envelope (see Figure 2). We hypothesized that the red ink would be more effective in getting respondents' attention and prompting them to respond. These treatments were applied in the initial mail and all follow-up reminders.

We found no apparent difference in final return rates between the two treatments (Wald $\left.\chi_{\mathrm{DF}=1}^{2}=1.2587 ; p=0.26\right)$. However, analysis revealed a statistically significant interaction effect, whereby the red ink treatment appeared to increase response rates among cases that were nonrespondents in the prior collection cycle (Wald $\left.\chi_{\mathrm{DF}=1}^{2}=4.3499 ; p=0.04\right)$. In addition, another statistically significant interaction showed that the effect of the red ink on response rates differed among wholesale industry subgroups (Wald $\chi_{\mathrm{DF}=2}^{2}=4.9136 ; p=0.09$ ). The red ink appeared to increase response rates among the industry subgroup Agents, Brokers, and Electronic Markets (ABEM) relative to other types of wholesalers.

\subsubsection{Envelope Experiment \#2: 2015 Annual Retail Survey}

In the 2015 Annual Retail Survey (ARTS), we compared two sizes of envelope. As noted above, this experiment was the result of a recommendation from past respondents participating in focus groups to evaluate outreach strategies, who suggested a larger envelope might be more effective in getting respondents' attention. In order to determine the effects of a different sized envelope, in this experiment, the treatment group received initial and follow-up mailings in half-page-sized envelopes (9.5" 6 "); the control received initial and follow-up mailings in standard letter-sized envelopes (9.5" $\mathrm{x} 4$ "). Aside from size, the two types of envelopes were identical in appearance. Figure 3 shows minimal differences in return rates between the two treatments, which reached statistical significance only at the due date $(p=0.021)$. We also found a statistically significant difference in mean days from mailout to return, with the larger-envelope group checking in on average in 36.7 days, compared to 36.12 days for the standard envelope group $\left(\mathrm{F}_{\mathrm{DF}=1}=4.37 ; p=0.04\right)$ (Hernandez 2016). However, this difference of less than one day has little value in practice.

\subsection{Contact Strategy \#2: Sequence}

We conducted two experiments involving enhanced mail contact sequences, with control groups receiving the typical contact sequences. 


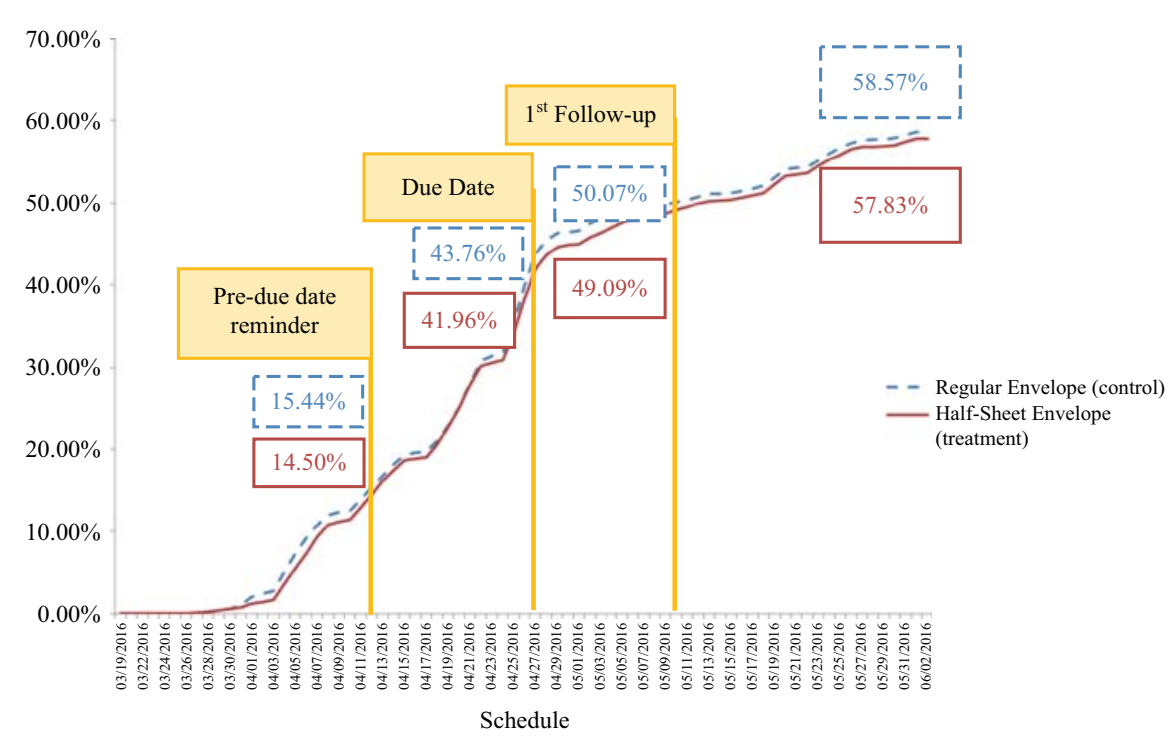

Fig. 3. Return rates for 2015 ARTS.

\subsubsection{Sequence Experiment \#1: Business Professional and Classification Survey}

The first sequence experiment was conducted with the Business Professional and Classification Survey (SQ-CLASS), which is a quarterly survey of businesses in the service sector industries with new or reactivated EINs ("births"). SQ-CLASS requests information necessary to classify the industry for new locations and incorporate them into the sampling frames of the Census Bureau's other service sector surveys. An important feature of this survey is that it is often completed by respondents who do not have prior experience with the Census Bureau's business surveys. Because larger companies are frequently sampled for multiple surveys (certainty cases), and the Census Bureau's business surveys' samples are generally longitudinal, with samples being used for multiple collection cycles, respondents often develop reporting routines to make response preparation more efficient in subsequent survey cycles (Willimack and Nichols 2010; Willimack et al. 1999). Therefore, the SQ-CLASS experiment offered an opportunity to evaluate the contact strategy with companies likely not to be biased by prior survey experience.

The SQ-CLASS experimental treatment involved the addition of a pre-due-date reminder letter sent approximately three weeks after the initial request letter and approximately two weeks before the survey due date. The pre-due-date reminder letter was very similar in content and appearance to the initial letter and other follow-up reminder letters. The sample consisted of 15,369 presumed businesses that were nonrespondents as of the creation of the pre-due-date reminder mail file; 4,640 were randomly assigned to the treatment group, and 10,729 to the control group.

Return rates for both groups increased as they approached the due date, but the return rate for the group receiving the pre-due-date reminder quickly became significantly higher than that of the control group, and remained so through the end of the collection period 
$\left(\chi_{\mathrm{DF}=1}^{2}=1952.4897, p<.0001\right)$. Comparison of mean return rates shows that respondents that received the pre-due-date reminder letter checked-in in significantly fewer days on average (mean $=42.2$ ) than those that did not receive the extra letter $\left(\right.$ mean $\left.=49.9 ; \quad F_{D F=1}=199.47 ; p<.0001\right)$. Comparison of mean numbers of nonresponse follow-up telephone calls to businesses shows that respondents who received the pre-due-date reminder letter received significantly fewer calls on average $($ mean $=1.8)$ than those who did not receive the extra letter (mean $=2.2$; $\left.\mathrm{F}_{\mathrm{DF}=1}=116.73 ; p<.0001\right)$.

\subsubsection{Sequence Experiment \#2: 2014 Annual Retail Trade Survey}

The second sequence experiment was conducted with the 2014 Annual Retail Trade Survey (ARTS), which is a survey of businesses engaged in retail and accommodations (food service, hotels, etc.) industries. This experiment involved a two- (Accelerated Follow-up (AFU) or Normal Follow-up (CNTL)) -by-two (Pre-due-date reminder (PDD) or No reminder) factorial design that investigated the addition of a pre-due-date reminder, the acceleration of the follow-up schedule and their interaction. Figure 4 illustrates the collection strategy and timing for the four treatment conditions. In addition to a pre-duedate reminder to increasing overall response, we also hypothesized that decreasing the latency of the post-due date follow-up would decrease the time to respond.

Figure 5 shows the return rate for each of the four experiment groups. The thickness of the bands represents $90 \%$ confidence intervals. Just prior to the due date (DD), responses from the groups that received the pre-due-date reminder (PDD) started to accumulate more quickly than for the other two groups. Similarly, responses from the groups that received the accelerated follow-up (AFU) began to increase more quickly from those that did not receive this treatment. The normal follow-up mailing (FU) groups began to increase at approximately the same interval after the follow-up was sent as the AFU group. The final return rates from all three experimental treatment groups were significantly higher than that of the control group (Langeland and Tuttle 2016).

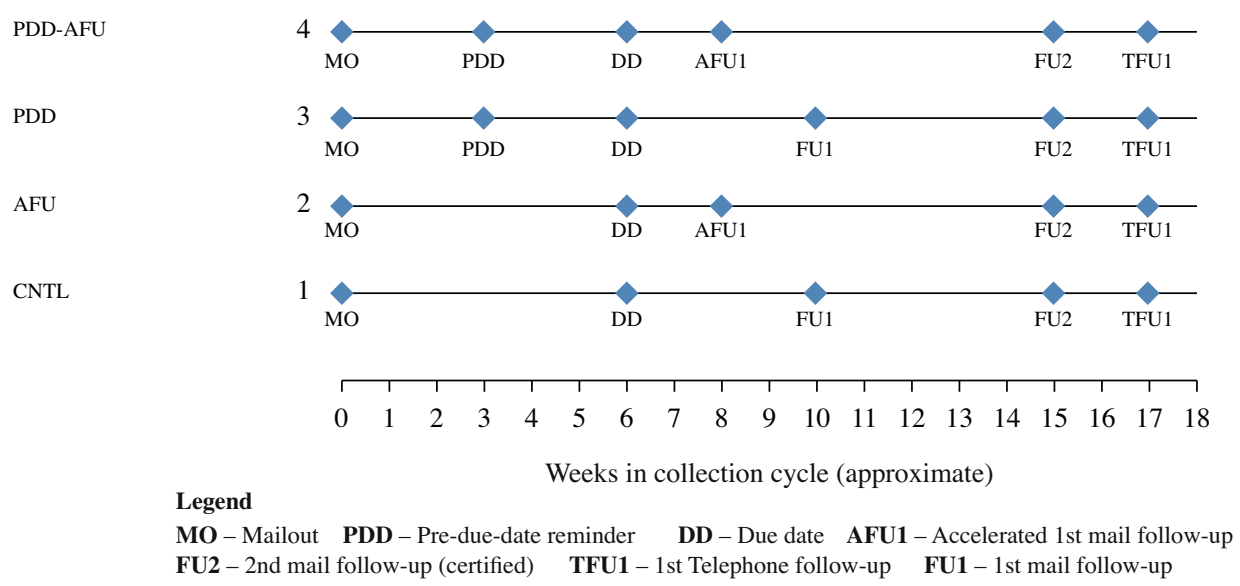

Fig. 4. 2014 ARTS mail sequences. 


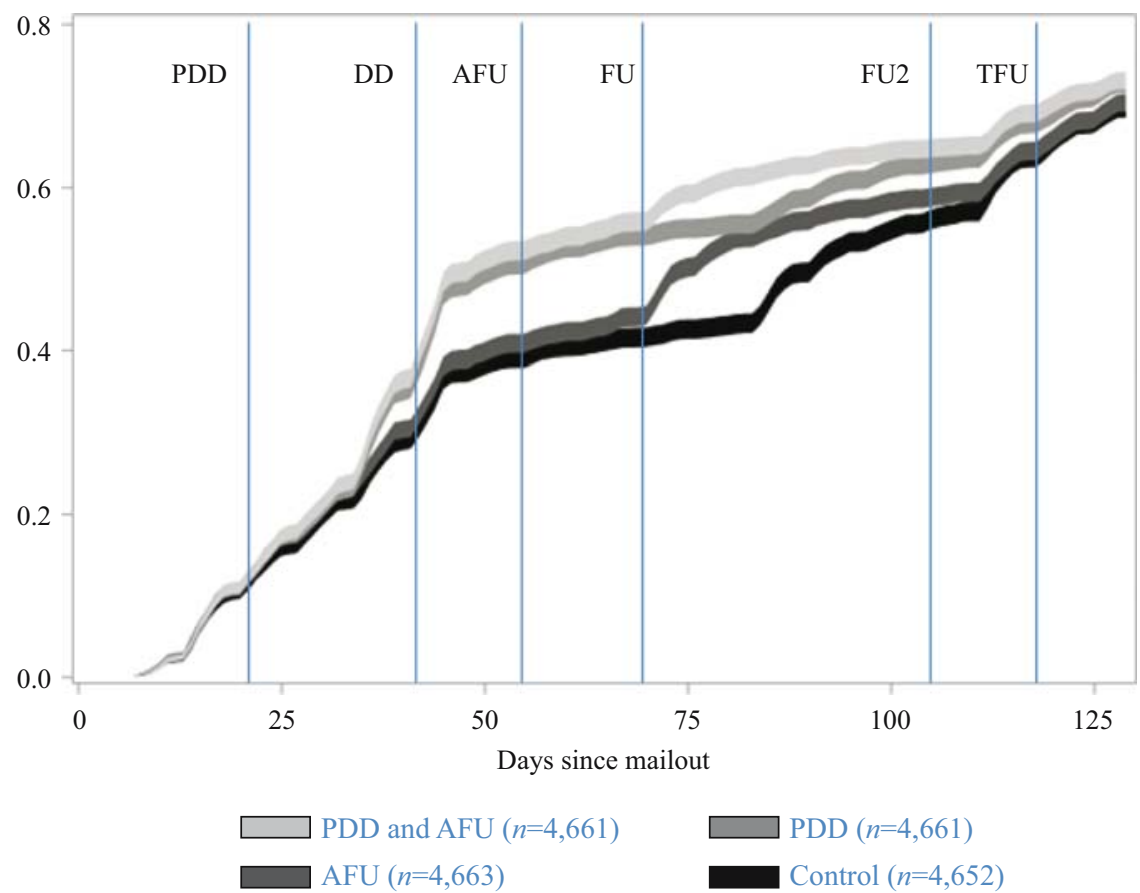

Fig. 5. Cumulative return rates for 2014 ARTS experiment groups.

\subsection{Contact Strategy \#3: Messages}

We conducted an experiment with the Services Annual Survey (SAS) to test alternative messages, which were included as flyers accompanying the usual survey letters. SAS collects details of revenues, expenses, and other financial information on an annual basis from businesses in the service sector. In this experiment, we compared the effects of flyers with three different messages intended to enhance the perceived value of the survey or reduce the perceived cost of participation. This experiment was intended to test the hypothesis that respondents who are directly exposed to information about the survey's results or the important uses of the results would place a higher value on the survey and on their cooperation with the survey, with detectable effects on timeliness and overall response.

The first flyer (Appendix 1) presented information about SAS, including key uses and users of SAS data products, and a colorful table showing total annual revenues for six industries collected by the survey over the preceding 11 years. This flyer promotes a message that SAS serves as an important source of information used by businesses, trade associations, journalists, and other government agencies. The chart showing changes in the selected industries' revenues over time, including the economic downturn during the 2008 recession, was intended to capture respondents' attention and tell a story about the economic fortunes of the service sector, a story made possible by SAS and businesses' participation in the survey.

The second flyer (Appendix 2) advertised the Census Business Builder (BB) tool, an application on the Census Bureau's website intended to be used by people looking to open 
or expand a business. The tool allows users to create customized reports containing summary economic and demographic data for any desired geographic areas for which the Census Bureau publishes statistics. The flyer does not refer to SAS specifically, but states that the Business Builder tool and other Census Bureau data products rely on "the participation of businesses like yours in our surveys." The use of this flyer was intended to see if respondents would associate their survey participation with the broader mission of the Census Bureau and its contribution to society.

The third flyer (Appendix 3) presented information about electronic reporting (ER), with illustrations showing the steps for accessing the online reporting system, and listing some of the burden-reducing features of the instrument. As a more informative and visually appealing version of other ER flyers routinely used in production (which typically lack illustrations, and have very simple formatting), this flyer was included in the experiment to compare messages about the benefits of electronic reporting (i.e., reducing the perceived cost) to those about the benefits of the surveys themselves (i.e., enhancing the perceived value).

Each treatment group was assigned one of three flyers in addition to a standard letter. The control group received only a standard letter. All groups received the same package for initial request and follow-up reminders.

We provide comparisons at day 40 (four days after the due date), and at day 100, the latest date for which data were available at the time of analysis. Results from regression analysis with prior respondents (Figure 6) show small but statistically significant differences. Most of the observable differences are associated with Flyer 3 (ER). Overall, Flyer 3 appears to be associated with response that is $1.2 \%$ lower than the no-flyer treatment across all industry subgroups at day 40, though the difference is no longer significant at day 100 .

In addition, Figure 6 shows several statistically significant interaction effects of the various flyers between different industry subgroups. For instance, the effect of the ER flyer on response rate varies by industry subgroup. It appears to exacerbate slightly the negative effect in Finance, while offsetting it in Healthcare, relative to its effect in the reference group. However, the effect appears to diminish somewhat by day 100. A statistically significant interaction effect found for the Business Builder flyer appears to slightly diminish response rates in the Healthcare industry, relative to the reference group, and disappears by day 100 .

\section{Summary and Discussion}

In this section we will summarize the results of the experiments and attempt to interpret them through our model of business survey communication and action.

\subsection{Envelope Experiments}

Printing the survey due date and "past due" in red ink did not improve survey response overall, but did increase response from prior-year nonrespondents and, rather modestly, from one industry subgroup. Perhaps equally significant from a practical standpoint, the red ink did not negatively affect response from prior respondents, so we purport that this strategy may be implemented without threatening already-cooperative respondents. 


\begin{tabular}{|c|c|c|c|c|c|c|}
\hline $\begin{array}{l}\text { Analysis of Maximum } \\
\text { Likelihood Estimates }\end{array}$ & & & & & & \\
\hline \multirow[b]{2}{*}{ Parameter } & \multicolumn{3}{|c|}{ Change in $\operatorname{Pr}(\operatorname{Resp})$} & \multicolumn{3}{|c|}{ Change in $\operatorname{Pr}(\operatorname{Resp})$} \\
\hline & Estimate & $\begin{array}{l}\text { wrt to } \\
\text { Reference }\end{array}$ & $\begin{array}{l}\mathrm{Pr}>\mathrm{Chi} \\
\mathrm{Sq}\end{array}$ & Estimate & $\begin{array}{l}\text { wrt to } \\
\text { Reference }\end{array}$ & $\begin{array}{l}\text { Pr>Chi } \\
\text { Sq }\end{array}$ \\
\hline Intercept & 0.009 & 0.00 & 0.4966 & $1.179 * *$ & 0.145 & $<.0001$ \\
\hline Finance $^{1}$ & $0.226^{* *}$ & 0.056 & $<.0001$ & $-0.260 * *$ & -0.050 & $<.0001$ \\
\hline Healthcare $^{1}$ & $-0.068^{* *}$ & -0.017 & 0.0002 & $0.070^{* *}$ & 0.012 & 0.0013 \\
\hline Information $^{1}$ & $-0.068^{*}$ & -0.017 & 0.0219 & 0.003 & 0.000 & 0.9372 \\
\hline Transportation $^{1}$ & $-0.071 *$ & -0.018 & 0.0067 & 0.043 & 0.008 & 0.1625 \\
\hline SAS results flyer ${ }^{2}$ & 0.016 & 0.004 & 0.4285 & 0.016 & 0.003 & 0.516 \\
\hline Business Builder flyer $^{2}$ & 0.030 & 0.007 & 0.1457 & -0.006 & -0.001 & 0.7975 \\
\hline ER flyer $^{2}$ & $-0.046^{*}$ & -0.012 & 0.0233 & -0.017 & -0.003 & 0.4793 \\
\hline Finance $\times$ SAS flyer ${ }^{3}$ & 0.060 & 0.015 & 0.181 & 0.064 & 0.011 & 0.2099 \\
\hline Finance $\times \mathrm{BB}$ flyer $^{3}$ & 0.060 & 0.015 & 0.1837 & 0.054 & 0.010 & 0.2806 \\
\hline Finance $\times$ ER flyer ${ }^{3}$ & $-0.127^{*}$ & -0.032 & 0.0046 & $-0.127 * *$ & -0.024 & 0.0098 \\
\hline Healthcare $\times$ SAS flyer ${ }^{3}$ & 0.004 & 0.001 & 0.9088 & 0.036 & 0.006 & 0.3487 \\
\hline Healthcare $\times \mathrm{BB}$ flyer ${ }^{3}$ & $-0.077 *$ & -0.019 & 0.015 & -0.031 & -0.006 & 0.4202 \\
\hline Healthcare $\times$ ER flyer ${ }^{3}$ & $0.087 * *$ & 0.022 & 0.0063 & $0.088^{*}$ & 0.015 & 0.021 \\
\hline Information $\times$ SAS flyer $^{3}$ & 0.039 & 0.010 & 0.4478 & -0.029 & -0.005 & 0.6342 \\
\hline Information $\times \mathrm{BB}$ flyer ${ }^{3}$ & 0.012 & 0.003 & 0.8065 & -0.003 & -0.001 & 0.9616 \\
\hline Information $\times$ ER flyer ${ }^{3}$ & 0.002 & 0.000 & 0.9741 & -0.024 & -0.004 & 0.6876 \\
\hline $\begin{array}{l}\text { Transportation } \times \text { SAS } \\
\text { flyer }^{3}\end{array}$ & -0.071 & -0.018 & 0.1169 & -0.049 & -0.009 & 0.3587 \\
\hline $\begin{array}{l}\text { Transportation } \times B B \\
\text { flyer }^{3}\end{array}$ & 0.034 & 0.008 & 0.4531 & 0.001 & 0.000 & 0.9904 \\
\hline $\begin{array}{l}\text { Transportation } \times E R \\
\text { flyer }^{3}\end{array}$ & -0.008 & -0.002 & 0.852 & 0.039 & 0.007 & 0.4702 \\
\hline
\end{tabular}

${ }^{1}$ Reference group $=$ all other sectors combined.

${ }^{2}$ Reference group $=$ control (no flyer) treatment.

${ }^{3}$ Reference group $=$ all-other-sectors group and no-flyer treatment. ${ }^{*} p<.05 .{ }^{* *} p<.01$

Fig. 6. Effects of flyers by industry subgroup at day 40 and day 100; return rates from cases that responded in the prior year (2015 SAS).

The envelope-size experiment revealed no improvement in response from larger envelopes, but rather the opposite at one point in time. However, the differences between treatment groups were small and not practically significant, so use of this strategy should not be discouraged out of hand without further research.

\subsection{Sequence Experiments}

Of the three types of strategies tested, the greatest success clearly came from increasing the number and frequency of contacts. The two sequence experiments showed a significant improvement in timeliness of response and overall response for the treatments groups receiving the additional reminder before the due date. The 2014 ARTS experiment also showed a benefit from accelerating post-due-date reminders, and from combining the 
accelerated follow-up with the pre-due-date reminder. This latter finding corroborates other research indicating the existence of an additive effect from multiple contacts in a sequence (Dillman et al. 2009). The success of these experiments has resulted in the implementation of pre-due-date reminders and accelerated follow-ups as a standard strategy across the Census Bureau's business surveys.

\subsection{Message Experiment}

Overall, the test of messages in survey communications showed mixed results. Messages promoting electronic reporting were associated with overall reduced returns, and produced opposite results in two industry subgroups in the SAS experiment. It should be noted that the Finance industry subgroup tends to report earlier than the other groups identified in the experiment (based on the higher response propensity at day 40 compared to day 100), and in this context the ER flyer may have interfered with otherwise-effective response processes. By contrast, the later-reporting Healthcare subgroup reacted positively to the ER flyer at both points in time, suggesting receptiveness to encouragement toward timelier reporting. The other two flyers showed no improvement in returns. Flyer 1 (SAS), presenting uses of the survey data and select results, had no significant impact on returns, and Flyer 3 (BB) about the Census Business Builder tool had an early negative effect on the Healthcare subgroup, which disappeared later in collection.

\subsection{Reflecting on Business Survey Decision-Making and Response Processes}

Returning to the questions we posed at the beginning of this article, what do these results suggest about the likelihood of getting businesses to respond to surveys and to do so in a timely fashion? To answer this, we must consider the possible effects of our contact strategies on business survey decision-making and response processes, specifically the dimensions of awareness, consideration, prioritization, and action from our model.

Printing the survey due date and past-due notice on the envelope in red ink appears to have caught the attention of prior nonrespondents as well as respondents in the Agents, Brokers, and Electronic Markets (ABEM) subgroup. Prior nonrespondents overall may have interpreted the red ink in the context of their previous nonparticipation and perceived that the Census Bureau would be less tolerant of continued nonresponse. We also speculate that the ABEM subgroup may experience a higher degree of government regulation than other industry subgroups, which made them sensitive to the enhanced envelope labeling for fear of consequences of nonresponse. We thus speculate that the red ink acted on all four components of our model. We acknowledge these may be spurious correlations, but they suggest that envelope labeling is worthy of further investigation and replication.

The negative effect on early response of the larger envelopes suggests that they were processed differently than normal mail. Perhaps larger envelopes are an indication of junk mail to business mailroom staff; if mail is sorted on the basis of what is obviously important, the larger envelopes may have been set aside for later sorting, thus delaying delivery to decision-makers and respondents. It is also possible that the larger envelopes sat in respondents' mailboxes longer without being opened because they did not look official or differed from their expectations of the appearance of official government mail. 
Awareness and consideration of the requests may have been hindered by the larger envelopes, with the result of precluding prioritization and action.

The results of the message flyers suggest both positive and negative effects on respondents' decisions to participate. As noted above, supplemental materials included in survey mail packages may be readily discarded as the critical information that facilitates response (log-in credentials, contact information for assistance, and survey due date) are found in the letter, so a lack of a discernible effect of our flyers would not be surprising. Respondents may be likely only to retain the letter and discard anything else that is not perceived as important. As the electronic reporting flyer contained useful information about the features of the reporting system and the steps for accessing it, it is reasonable to see the potential value of retaining it for reference. Thus the ER flyer may have affected the consideration and prioritization of the request by reducing the perceived burden and enhancing the perceived capacity, resulting in quicker action.

The slight negative impact of the Business Builder flyer is curious. It is possible that Healthcare respondents spent time exploring the online tool that they would have spent working on the survey. Perhaps they did not perceive any value in the tool or had a lessthan-satisfying experience using it, which resulted in reduced motivation for completing the survey. Snijkers and Jones (2013) state that all survey communications may be interpreted through and mediated by businesses' perceptions of their own corporate image, with the implication that some may not view economic statistics favorably. In the case of the Business Builder flyer, an increased awareness of the availability of survey data may have had a negative effect on consideration, prioritization, and action.

The clearest and most positive results were obtained from increasing the frequency and number of contacts. The improved return rates from the more-frequent contact treatments suggest that some respondents will be willing and able to respond more quickly if they are simply made aware of the request more often. More numerous and frequent contacts may also affect the perceived urgency of the request, thus increasing the chances of both effective routing of a request through gatekeepers and consideration and prioritization by decision-makers.

The burden associated with survey response can vary greatly due to differences in company size, organizational complexity, scope of activity with regard to industry classification, and so on. Smaller, simpler, and more homogeneous companies may not require as much time to respond, and so may react favorably to more-frequent contacts than larger and more diverse companies. The same may hold true for less complicated surveys regardless of company size and complexity. The combination of variables related to survey and business complexity make it unlikely that a "one-size-fits-all" optimal interval between contacts can be found, and indicate a need to tailor the timing of contacts.

Since most of our experiments were conducted with recurring surveys, the impact of our contact strategies may have been mitigated by the use of reporting routines in cases where the survey was anticipated and coordination and scheduling of resources took place. Late responders may simply be unable (or unwilling) to report earlier, due to workload early in the survey collection cycle, timing of availability of data, extent of distribution of response tasks among multiple respondents and business units, and so on.

This summary of our research indicates the likelihood that enhanced communication strategies affect companies differently, and perhaps systematically, with regard to 
business characteristics. We plan to conduct further analyses to examine the impact of our experimental treatments with regard to factors such as company size/complexity, industry subgroup, certainty of selection, and historical reporting behaviors.

An important limitation of experiments of the type reported in this article is a lack of insight into the specific impacts of survey communication strategies on respondents and other actors in business survey response processes. Future contact strategies experiments should be coupled with qualitative research with respondents to examine their perceptions of the value (if any) of enhanced survey communication strategies and to explore further their effects on survey decision-making and participation processes.

\subsection{Cost Comparison}

A major limitation of the research presented in this article is a lack of information about any cost savings that may have been realized through the use of enhanced contact strategies. This is the result of our assumption that any improvements in response rates and timeliness would likely be associated with substantial cost savings simply by reducing the numbers of cases referred to more expensive telephone follow-up operations. Increasing the number of mailings in the sequence experiments, including flyers in the message experiment, and using larger envelopes in the envelope experiment may have incurred somewhat higher costs than the typical mailout strategies, but these increased costs were considered negligible in the context of the large scale of our survey operations. Thus, we did not find it necessary to include cost comparisons in the planning and evaluation of these experiments. 


\section{Appendix 1}

2015 SAS results flyer

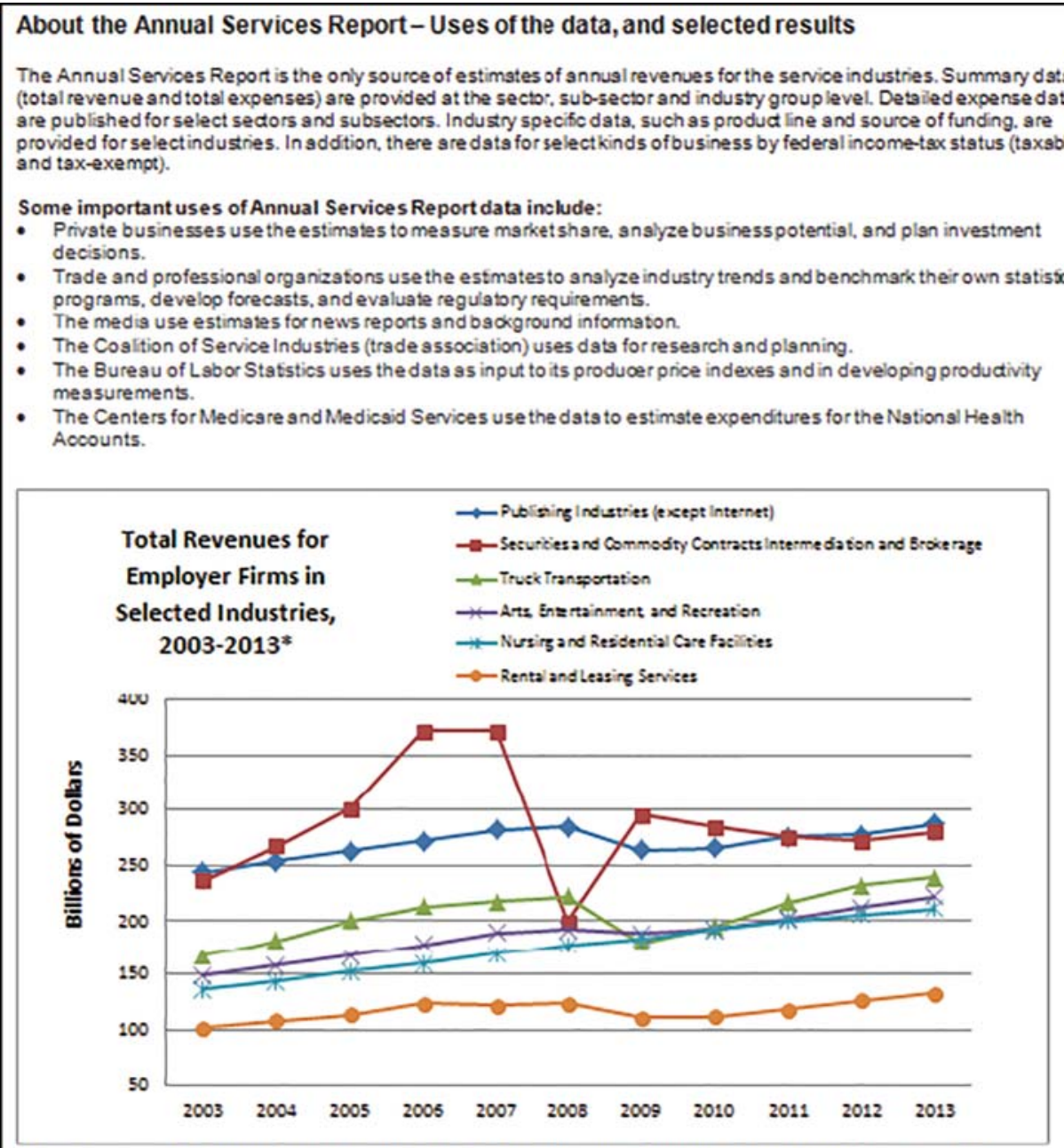

"The data presented in this table are based on estimates released on November 19,2014 . Please note that these eatimates will be benchmarked to the 2012 Economic Census and are not considere d fnal. Revised eatimates are scheduled for rele ase in early 2016.

Find more data about the American people, places. and economy at census.gov.

For more information aboutthe Annual Services Report, please visit econhelp.census.govisas. 


\section{Appendix 2}

Business Builder flyer

\section{Census Business Builder: Small Business Edition}

\section{Helping Small Business Owners Find Their Place in the World}

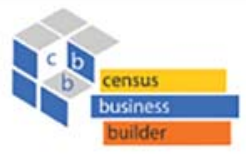

Census Business Builder is a suite of services that provides selected demographic and economic data from the Census Bureau tailored to specific types of users in a simple to access and use format. This suite currently includes the Small Business Edition, a proposed Chamber of Commerce Edition, and will include other tailored editions in the future. To access the tool, please visit: $h t t p: / / c e n s u s . g o v / d a t a / d a t a-t o o l s / c b b . h t m l$

The Census Business Builder and many other data products are only possible because of the participation of businesses like yours in our surveys, and we thank you. Your response makes a difference.

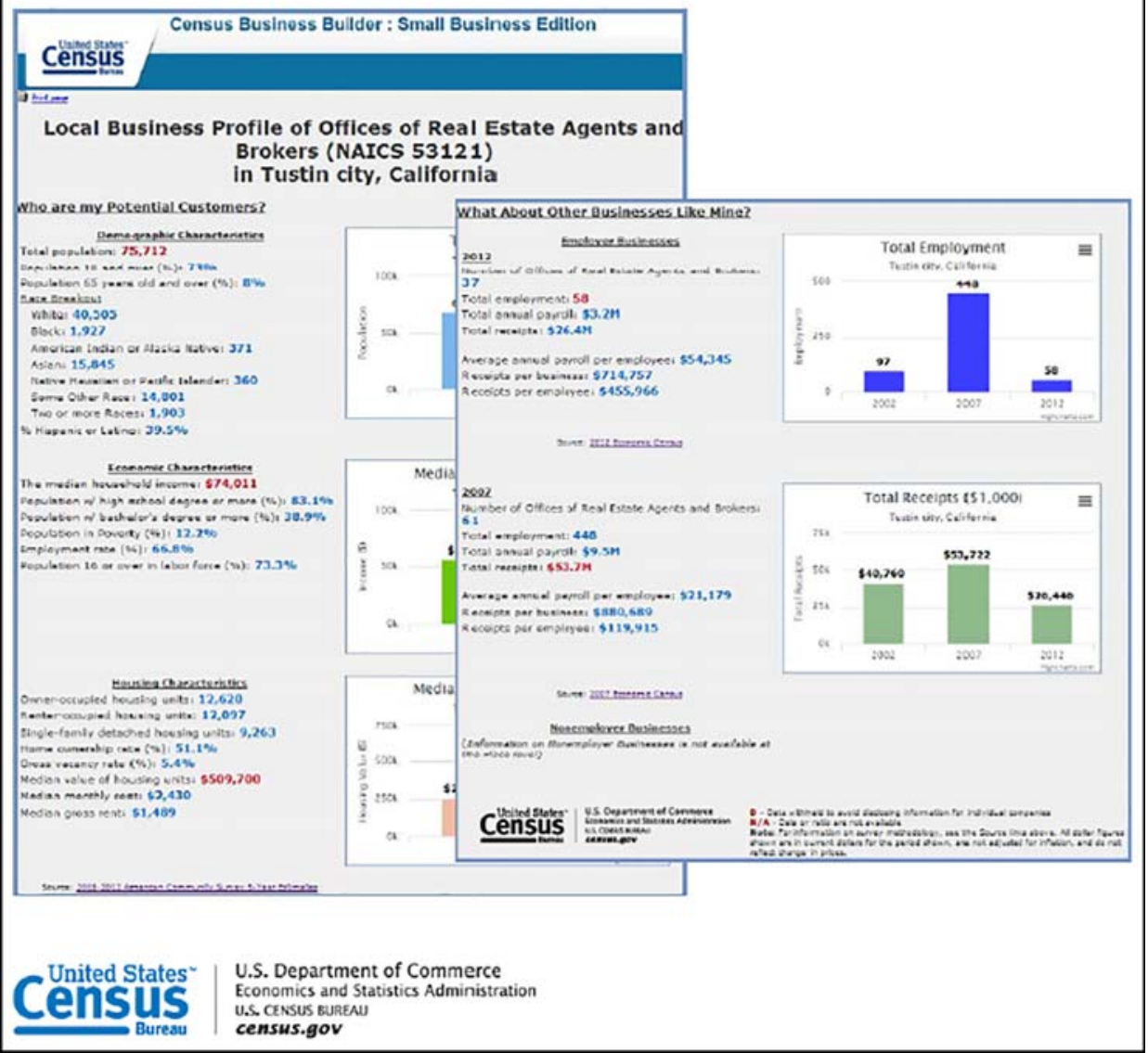




\section{Appendix 3}

Electronic reporting flyer

\section{Complete the 2015 Annual Services Report online using our efficient, secure, and user-friendly electronic reporting system.}

To start, visit our secure site - https://econhelp.census.gov/sas and click the "Survey Log in" button.

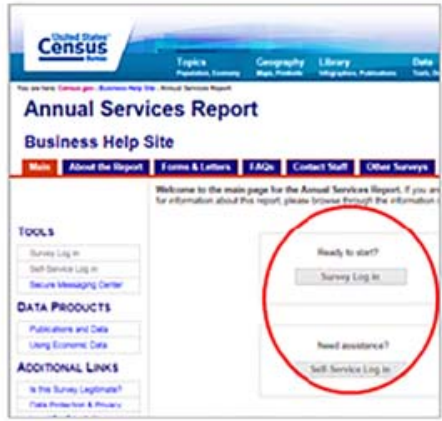

You can also request a time extension and check your filing status - click"Self-Service Log In."

Log in using the User ID and Password found on the letter we mailed to your company.

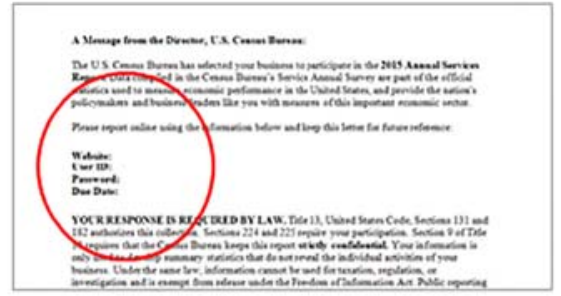

Fıun the Main Menu, click the "Stant" buttun for each ıpuit listed.

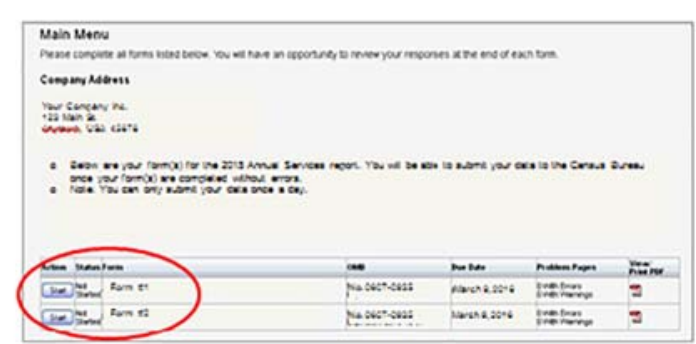

Features of our electronic reporting system:

Downloadable workshœets

- To download a worksheet to comple your data before reporting online, select one of the links under the "View/Print PDF" column on the main menu.

- Please note that if you have more than one report listed on your main menu, the worksheets and specia instructions may differ.

Auto-save

- Your data are saved every time you click "Save and continue" or "Back" on the page.

- Please note that your data are not saved if you use your browser's navigation buttons.

- You can log out and return where you left off as often as you need before submitting the completed report.

\section{Skips and checks}

- Our system automatically skips questions that do not apply to your company.

- It also checks for common errors.

Find more data about the American people, places, and economy at census.gov.

For more information about the Annual Services Report, visit econhelp.census.gov/sas

\section{Culiked Stato}




\section{References}

Barron, S., C. Reiser, M. Bentley, J. Hill, and A. Meier. 2012. "2010 Census Deadline Messaging and Compressed Mailing Schedule Experiment." Paper presented at the 2012 Joint Statistical Meetings, San Diego, CA.

Barry, T. E. 1987. "The Development of the Hierarchy of Effects: An Historical Perspective." Current Issues and Research in Advertising 10(1-2): 251-295.

Barth, D., M. Zelenak, M. Asiala, E. Castro, and A. Roberts. 2016. 2015 Envelope Mandatory Messaging Test: Final Report. Suitland, MD: U.S. Census Bureau. Available at: https:/www.census.gov/content/dam/Census/library/working-papers/ 2016/acs/2016_Barth_01.pdf (accessed April 2018).

Bavdaž, M. 2010. "The Multidimensional Integral Business Survey Response Model." Survey Methodology 36(1): 81-93.

Britt, R. and F. Featherston. 2007. "Increasing Survey Cooperation: Motivating Chronic Late Responders to an Annual Survey." Paper presented at the Third International Conference on Establishment Surveys, June 18-21, 2007, Montreal, Quebec, Canada.

Chun, Y.I. and K. Robertson. 1995. "The Effects of Advance Letters and Reminder/Thank You Letters on Reducing Nonresponse in an Establishment Survey: An Experimental Study." Washington, D.C., USA: Bureau of Labor Statistics. Available at: https://stats.bls.gov/osmr/pdf/st950020.pdf (accessed April 2018).

Cialdini, R. 1984. Influence: The Psychology of Persuasion. NY: Quill.

Claveau, J. and C. Turmelle. 2012. "An Embedded Experiment to Test Non-Response Follow-Up Strategies when Using Electronic Questionnaires.” Paper presented at the Conference of European Statisticians, June 6-8, 2012. Paris, France.

Crawford, S., M. Couper, and M. Lamias. 2001. "Web Surveys: Perceptions of Burden." Social Science Computer Review 19(2001): 146-162. Doi: http://dx.doi.org/ 10.1177/ 089443930101900202.

Davis, W. and N. Pihama. 2009. "Survey Response as Organizational Behavior: An Analysis of the Annual Enterprise Survey, 2003-2007." New Zealand Association of Economists Conference, July 1-3, 2009. Wellington, New Zealand.

Dillman, D., J. Smith, and L. Christian. 2009. Internet, Mail, and Mixed Mode Surveys: the Tailored Design Method. Hoboken, NJ: John Wiley \& Sons.

Dillman, D., E. Singer, J. Clark, and J. Treat. 1996. "Effects of Benefits Appeals, Mandatory Appeals, and Variations in Statements of Confidentiality on Completion Rates for Census Questionnaires." Public Opinion Quarterly 60(3): 376-389. Doi: https://dx.doi.org/10.1086/297759.

Eggleston, C., J. Childs, and E. Nichols. 2016. "Conjoint Analysis of Survey Invitation Messages: A New Method to Understand What Moves People to Respond.” Presented at the Federal Computer-Assisted Survey Instrument Collection Conference, May 3-4, 2016. Suitland, MD.

Erikson, J. and P. Hartwig. 2012. "Trying to Improve Response Rates by Lowering the Perceived Response Burden of a Survey." Presented at the Fourth International Conference on Establishment Surveys, June 11-14, 2012. Montreal, Quebec, Canada. 
Franklin, J., J. Simpson, J. Wine, and N. Paoli. 2007. "Developing a Contact Strategy to Maximize Self-Administered Web Participation." Presented at the American Association for Public Opinion Research Conference, May 17-20, 2007. Anaheim, CA. Fulton, J., G. Morales, and J. Childs. 2016. "Effects of Messaging to Encourage Response to the American Community Survey." Presented at the American Association of Public Opinion Research Conference, May 12-15, 2016. Austin, TX.

Giesen, D. 2012. "Exploring Causes and Effects of Perceived Response Burden.” Paper presented at the Fourth International Conference on Establishment Surveys, June 11-14, 2012. Montreal, Quebec, Canada.

Groves, R., D. Cantor, M. Couper, K. Levin, K. McGonagle, E. Singer, and J. Van Hoewyk. 1997. "Research Investigations in Gaining Participation from Sample Firms in the Current Employment Statistics Program." In proceedings of the Survey Research Methods Section, American Statistical Association: 289-294. Anaheim, California, USA, August 10-14, 1997.

Groves, R., R. Cialdini, and M. Couper. 1992. "Understanding the Decision to Participate in a Survey." Public Opinion Quarterly 56(4): 475-495. Doi: http://dx.doi.org/ $10.1086 / 269338$.

Groves, R. and M. Couper. 1998. Nonresponse in Household Interview Surveys. Hoboken, NJ: John Wiley \& Sons.

Haraldsen, G. 2013. "Quality Issues in Business Surveys.” In Designing and Conducting Business Surveys, edited by Snijkers, G., Haraldsen, G., Jones, J. and Willimack, D. John Wiley and Sons: Hoboken, NJ.

Hedlin, D., H. Lindkvist, H. Bäckström, and J. Erikson. 2008. “An Experiment on Perceived Survey Response Burden among Businesses.” Journal of Official Statistics 24(2): 301-318.

Her Majesty's Revenue Commission. 2010. Large Business Methodology Review: Stage Two Report. Her Majesty's Revenue and Customs Research Report 98. London, UK: Her Majesty's Revenue Commission. Available at: https:/www.gov.uk/government/ publications/government-sponsored-research-of-large-businesses (accessed April 2018).

Hernandez, A., C. Fan, and A. Tuttle. 2016. "The Effect of a Pre-Due Date Reminder Letter on Nonresponse in a Business Survey." Presented at the American Association of Public Opinion Research Conference, May 12-15, 2016. Austin, TX.

Herndandez, A. 2016. 2015 ARTS Contact Strategies Experiment Results. Suitland, MD: U.S. Census Bureau. Internal report.

Hughes, T. and J. Tancreto. 2015. "Refining the Web Response Option in the Multiple Mode Collection of the American Community Survey." Presented at the European Survey Research Association Conference, July 13-17, 2015. Reykjavik, Iceland.

Kaplowitz, M.D., T.D. Hadlock, and R. Levine. 2004. "A Comparison of Web and Mail Survey Response Rates.” Public Opinion Quarterly 68(1): 94-101. Doi: http://dx.doi.org/10.1093/poq/nfh006.

Keller, J. 2015. 2017 Economic Census Publicity and Outreach Phase 1: Focus Group Research. Suitland, MD: U.S. Census Bureau. Internal presentation.

Keller, S., R. Hough, T. Falconer, and K. Curcio. 2011. "Characteristics of Large Company Respondents to an Economic Survey." Presented at the 2011 Joint Statistical Meetings, July 30 - August 4, 2011. Miami Beach, FL. 
Landreth, A. 2002. Results and Recommendations from Cognitive Interviews with Selected Materials from the American Community Survey. Suitland, MD: U.S. Census Bureau. Available at: http://www.census.gov/srd/papers/pdf/ssm2003-10.pdf (accessed April 2018).

Landreth, A. 2003. SIPP Advance Letter Focus Group Results: Issues and Recommendations. Suitland, MD: U.S. Census Bureau. Available at: http://www.census. gov/srd/papers/pdf/ssm2003-07.pdf (accessed April 2018).

Landreth, A. 2004. "Survey Letters: A Respondent's Perspective." Paper presented at the American Association for Public Opinion Research, May 13-16, 2004. Phoenix, Arizona.

Langeland, J. and A. Tuttle. 2016. "Improving Data Collection: Results from Two Contact Strategy Experiments in Economic Surveys." Presented at the Fifth International Conference on Establishment Surveys, June 20-23, 2016. Geneva, Switzerland.

Leslie, T., D. Griffin, P. McGovern, and D. Raglin. 2004. "Measuring the Impact of Questionnaire and Envelope Messages on Respondent Behavior." Presented at the Joint Statistical Meetings, August 8-12, 2004. Toronto, Ontario, Canada.

Lor, M., B. Bowers, and A. Krupp. 2017. "Tailored Explanation: A Strategy to Minimize Nonresponse in Demographic Items Among Low-Income Racial and Ethnic Minorities." Survey Practice 10(3). Doi: http://dx.doi.org/10.29115/SP-2017-0015.

Lorenc, B., M. Bavdaž, D. Diesen, R. Seljak, and V. Torres van Grinsven. 2012.

"Businesses as Users of Official Statistics." Paper presented at the Fourth International Conference on Establishment Surveys, June 11-14, 2012. Montreal, Quebec, Canada.

Lykes, V. and J. Meyers. 2017. "Got Mail? Drivers of Mail-to-Online Response Rates." Presented at the American Association of Public Opinion Research Conference, May 18-21, 2017. New Orleans, Louisiana.

Marquette, E., M. Kornbau, and J. Toribio. 2015. "Testing Contact Strategies to Improve Response in the 2012 Economic Census." Paper presented at the Joint Statistical Meetings, August 8-13, 2015. Seattle, Washington.

McCarthy, J., T. Wilson, and A. Dau. 2015. “Adept Adaptations: Developing Alternative Strategies in Adaptive Survey Designs." Presented at the Federal Committee on Statistical Methods Conference, December 1-3, 2015. Washington, D.C.

McCarthy, J., D. Beckler, and M. Qualey. 2006. “An Analysis of the Relationship Between Survey Burden and Nonresponse: If We Bother Them More, Are They Less Cooperative?" Journal of Official Statistics 22(1): 97-112.

Matthews, B. 2012. 2011 American Community Survey Internet Tests: Results from Second Test in November 2011. Suitland, MD: U.S. Census Bureau. Internal report.

Nichols, E. 2012. The April 2011 American Community Survey Internet Test: Attitudes and Behavior Study Follow up. Suitland, MD: U.S. Census Bureau. Available at: https://www.census.gov/content/dam/Census/library/working-papers/2012/acs/2012 Nichols_01.pdf (accessed April 2018).

Perrins, G., P. Phipps, J. Pinkos, T. Shaffer, G. Stamas, S. Suchman, C. Tucker, and S. Watkins. 2009. Results from the Occupational Employment Survey Letter and Brochure Experiment. Washington, D.C: Bureau of Labor Statistics. Internal report. 
Phipps, P. 2008. “The Occupational Employment Statistics (OES) Program: Cover Letter and Brochure Experiments." Presented at the Federal Computer-Assisted Survey Instrument Collection Conference, March 11-13, 2008. Washington, D.C.

Reiser, C. 2013. "Internet Response for the Decennial Census - 2012 National Census Test." Presented at the American Association of Public Opinion Research Conference, May 16-19, 2013. Boston, MA.

Shih, T. and X. Fan. 2008. "Comparing Response Rates from Web and Mail Surveys: A Meta-Analysis." Field Methods 20(3): 249-271. Doi: http://dx.doi.org/10.1177/ $1525822 X 08317085$.

Snijkers, G., B. Berkenbosch, and M. Luppes. 2007. "Understanding the Decision to Participate in a Business Survey." Paper presented at the Third International Conference on Establishment Surveys, June 18-21, 2007. Montreal, Quebec, Canada.

Snijkers, G. and J. Jones. 2013. "Business Survey Communication." In Designing and Conducting Business Surveys, edited by Snijkers, G., Haraldsen, G., Jones, J. and Willimack, D., 359-430. John Wiley and Sons: Hoboken, NJ.

Snijkers, G. and G. Haraldsen. 2013. "Managing the Data Collection." In Designing and Conducting Business Surveys, edited by Snijkers, G., Haraldsen, G., Jones, J. and Willimack, D., 431-457. John Wiley and Sons: Hoboken, NJ.

Tancreto, J. 2012. 2011 American Community Survey Internet Tests: Results from First Test in April 2011. Suitland, MD: U.S. Census Bureau. Internal report.

Tomaskovic-Devey, D., J. Leiter, and S. Thompson. 1994. "Organizational Survey Nonresponse.” Administrative Science Quarterly 39: 439-457. Doi: http://dx.doi.org/ $10.2307 / 2393298$.

Torres van Grinsven, V., I. Bolko, and M. Bavdaž. 2012. "Sources of Motivation in Business Surveys." Paper presented at the Fourth International Conference on Establishment Surveys, June 11-14, 2012. Montreal, Quebec, Canada.

Tulp, D., C. Hoy, G. Kusch, and S. Cole. 1991. "Nonresponse under Mandatory vs. Voluntary Reporting in the 1989 Survey of Pollution Abatement Costs and Expenditures (PACE)." In JSM Proceedings, Survey Research Methods Section. August 18-22, 1991. Alexandria, VA: American Statistical Association: 272-277.

Tuttle, A. 2009. "Establishment Respondents as Survey Managers: Using Survey Design

Features to Empower Respondents to Find and Recruit Knowledgeable Company Personnel for Assistance." Presented at the Federal Committee on Statistical Methodology Research Conference, November 2-4, 2009. Washington D.C.

Tuttle, A. 2011. Large Company Reporting Practices Program - Company Visits Highlights, Round 1. Suitland, MD: U.S. Census Bureau. Internal report.

Tuttle, A. 2016. "Developing Electronic Tools to Support the Logistical and Collaborative Needs of Respondents to the Economic Census." Presented at the Federal ComputerAssisted Survey Instrument Collection Conference, May 3-4, 2016. Suitland, MD.

Tuttle, A., K. Pick, R. Hough, and J. Mulrow. 2010. "Experimenting with Pre-contact Strategies for Reducing Nonresponse in an Economic Survey." In JSM Proceedings, Survey Research Methods Section. July 31 - August 5, 2010. Alexandria, VA: American Statistical Association: 5253-5262.

Tuttle, A. and D. Willimack. 2005. "Privacy Principles and Data Sharing: Implications of CIPSEA for Economic Survey Respondents.” Presented at the Federal Committee 
on Statistical Methodology Research Conference, November 14-16, 2005. Washington D.C.

Tuttle, A. and D. Willimack. 2012. "Social Network Analysis as a Tool for Assessing Data Quality and Respondent Burden in Establishment Surveys." Presented at the Fourth International Conference on Establishment Surveys, June 11-14, 2012. Montreal, Quebec, Canada.

Willimack, D., E. Nichols, and S. Sudman. 2002. "Understanding Unit and Item Nonresponse in Business Surveys." In Survey Nonresponse, edited by Groves, R. et al. New York: Wiley, 213-227.

Willimack, D. and E. Nichols. 2010. “A Hybrid Response Process Model for Business Surveys.” Journal of Official Statistics 26(1): 3-24.

Willimack, D., E. Nichols, and S. Sudman. 1999. "Understanding the Questionnaire in Business Surveys.” In JSM Proceedings, Survey Research Methods Section. August 8-12, 1999. Alexandria, VA: American Statistical Association: 889-94.

Willimack, D. and G. Snijkers. 2013. "The Business Context and its Implications for the Survey Response Process." In Designing and Conducting Business Surveys, edited by Snijkers, G., Haraldsen, G., Jones, J. and Willimack, D. page numbers. Wiley: Hoboken, NJ.

Zotti, A., L. Avenilla, S. Coffey, and G. Walejko. 2016. "The Effects of Sending a Pre-notice Postcard in a CAPI-conducted Survey." Presented at the American Association of Public Opinion Research Conference, May 12-15, 2016. Austin, TX.

Received October 2016

Revised December 2017

Accepted January 2018 